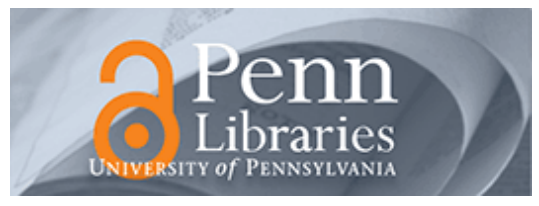

University of Pennsylvania

ScholarlyCommons

Marketing Papers

Wharton Faculty Research

7-10-2007

\title{
Global Warming: Forecasts by Scientists versus Scientific Forecasts
}

Kesten C. Green

Monash University

J. Scott Armstrong

University of Pennsylvania, armstrong@wharton.upenn.edu

Follow this and additional works at: https://repository.upenn.edu/marketing_papers

Part of the Environmental Sciences Commons

\section{Recommended Citation}

Green, K. C., \& Armstrong, J. S. (2007). Global Warming: Forecasts by Scientists versus Scientific

Forecasts. Retrieved from https://repository.upenn.edu/marketing_papers/133

Postprint version. To be published in Energy and Environment, 2007, 16 pages.

This paper is posted at ScholarlyCommons. https://repository.upenn.edu/marketing_papers/133

For more information, please contact repository@pobox.upenn.edu. 


\title{
Global Warming: Forecasts by Scientists versus Scientific Forecasts
}

\begin{abstract}
In 2007, the Intergovernmental Panel on Climate Changes Working Group One, a panel of experts established by the World Meteorological Organization and the United Nations Environment Programme, issued its updated, Fourth Assessment Report, forecasts. The Report was commissioned at great cost in order to provide policy recommendations to governments. It included predictions of dramatic and harmful increases in average world temperatures over the next 92 years. Using forecasting principles as our guide we asked, are these forecasts a good basis for developing public policy? Our answer is "no." To provide forecasts of climate change that are useful for policy-making, one would need to forecast (1) global temperature, (2) the effects of any temperature changes, (3) the effects of alternative policies, and (4) whether the best policy would be successfully implemented. Proper forecasts of all four are necessary for rational policy making. The IPCC Report was regarded as providing the most credible long-term forecasts of global average temperatures by 31 of the 51 scientists and others involved in forecasting climate change who responded to our survey. We found no references to the primary sources of information on forecasting methods despite the fact these are easily available in books, articles, and websites. In our audit of Chapter 8 of the IPCC's WG1 Report, we found enough information to make judgments on 89 out of a total of 140 forecasting principles. The forecasting procedures that were described violated 72 principles. Many of the violations were, by themselves, critical. We concluded that the forecasts in the Report were not the outcome of scientific procedures. In effect, they were the opinions of scientists transformed by mathematics and obscured by complex writing. Research on forecasting has shown that experts' predictions are not useful. Instead, policies should be based on forecasts from scientific forecasting methods. We have been unable to identify any scientific forecasts of global warming. Claims that the Earth will get warmer have no more credence than saying that it will get colder.
\end{abstract}

\section{Keywords}

accuracy, audit, climate change, evaluation, expert judgment, mathematical models, public policy

Disciplines

Environmental Sciences

Comments

Postprint version. To be published in Energy and Environment, 2007, 16 pages. 


\title{
Global Warming: Forecasts by Scientists versus Scientific Forecasts*
}

\author{
Kesten C. Green, Business and Economic Forecasting Unit, Monash University \\ c/o PO Box 10800, Wellington 6143, New Zealand. \\ kesten@kestencgreen.com; T +64 4976 3245; F +64 49763250 \\ J. Scott Armstrong†, The Wharton School, University of Pennsylvania \\ 747 Huntsman, Philadelphia, PA 19104, USA. \\ armstrong@,wharton.upenn.edu
}

(This paper is a draft of an article that is forthcoming in Energy and Environment.) Version 43 - July 10, 2007

\begin{abstract}
In 2007, the Intergovernmental Panel on Climate Change's Working Group One, a panel of experts established by the World Meteorological Organization and the United Nations Environment Programme, issued its updated, Fourth Assessment Report, forecasts. The Report was commissioned at great cost in order to provide policy recommendations to governments. It included predictions of dramatic and harmful increases in average world temperatures over the next 92 years. Using forecasting principles as our guide we asked, are these forecasts a good basis for developing public policy? Our answer is "no."

To provide forecasts of climate change that are useful for policy-making, one would need to forecast (1) global temperature, (2) the effects of any temperature changes, (3) the effects of alternative policies, and (4) whether the best policy would be successfully implemented. Proper forecasts of all four are necessary for rational policy making.

The IPCC Report was regarded as providing the most credible long-term forecasts of global average temperatures by 31 of the 51 scientists and others involved in forecasting climate change who responded to our survey. We found no references to the primary sources of information on forecasting methods despite the fact these are easily available in books, articles, and websites. In our audit of Chapter 8 of the IPCC's WG1 Report, we found enough information to make judgments on 89 out of a total of 140 forecasting principles. The forecasting procedures that were described violated 72 principles. Many of the violations were, by themselves, critical.

We concluded that the forecasts in the Report were not the outcome of scientific procedures. In effect, they were the opinions of scientists transformed by mathematics and obscured by complex writing. Research on forecasting has shown that experts' predictions are not useful. Instead, policies should be based on forecasts from scientific forecasting methods. We have been unable to identify any scientific forecasts of global warming. Claims that the Earth will get warmer have no more credence than saying that it will get colder.
\end{abstract}

Keywords: accuracy, audit, climate change, evaluation, expert judgment, mathematical models, public policy.

*Neither of the authors received funding for this paper.

$\dagger$ Information about J. Scott Armstrong can be found on Wikipedia. 
Research on forecasting has been conducted since the 1930s. Of particular value are comparative empirical studies to determine which methods are most accurate in given situations. The findings, along with the evidence, were first summarized in Armstrong $(1978,1985)$. The forecasting principles project, begun in the mid-1990s, summarized knowledge as evidence-based principles (condition-action statements) to provide guidance on which methods to use in a given situation. The project led to the Principles of Forecasting handbook (Armstrong 2001), which involved 40 authors (all internationally known experts on forecasting methods) along with 123 reviewers (also leading experts on forecasting methods). The summarizing process alone required a four-year effort.

Efforts have been made to ensure that these principles are easy to find. They have been freely available on forecastingprinciples.com, a site that has been first on Google searches for "forecasting" for many years. The directors' objective for the site is to summarize all useful knowledge on forecasting methods. There is no other source that provides evidence-based forecasting principles. The site is often updated, and a recent update of evidence on some of the key principles was published in Armstrong (2006).

Many of the principles go beyond common sense, and some are counter-intuitive. As a result, those who forecast in ignorance of the research literature are unlikely to produce useful predictions. For example, here are some of the well-established generalizations for situations involving long-term forecasts of complex issues where the causal factors are subject to uncertainty (as with climate):

- Unaided judgmental forecasts by experts have no value. This applies whether the opinions are expressed in words, spreadsheets, or mathematical models. It also applies regardless of how much scientific evidence is possessed by the experts. Among the reasons for this are:

a) Complexity: People cannot assess complex relationships through unaided observations.

b) Coincidence: People confuse correlation with causation.

c) Feedback: People making judgmental predictions typically do not receive unambiguous feedback they can use to improve their forecasting.

d) Bias: $\quad$ People have difficulty in obtaining or using evidence that contradicts their initial beliefs. This problem is especially serious for people who view themselves as experts.

- Agreement among experts is weakly related to accuracy. This is especially true when the experts communicate with one another and when they work together to solve problems, as is the case with the IPCC process.

- Complex models (those involving nonlinearities and interactions) harm accuracy because their errors multiply. Ascher (1978), refers to the Club of Rome's 1972 forecasts where, unaware of the research on forecasting, the developers proudly proclaimed, "in our model about 100,000 relationships are stored in the computer. Complex models also tend to fit random variations in historical data well, with the 
consequence that they forecast poorly and provide misleading conclusions about the uncertainty of the outcome. Finally, when complex models are developed there are many opportunities for errors and the complexity means the errors are difficult to find. Craig, Gadgil, and Koomey (2002) came to similar conclusions in their review of long-term energy forecasts for the US made between 1950 and 1980.

- Given even modest uncertainty, prediction intervals are enormous. For example, prediction intervals (ranges outside which outcomes are unlikely to fall) expand rapidly as time horizons increase, so that one is faced with enormous intervals even when trying to forecast a straightforward thing such as automobile sales for General Motors over the next five years.

- When there is uncertainty in forecasting, forecasts should be conservative. Uncertainty arises when data contain measurement errors, when the series are unstable, when knowledge about the direction of relationships is uncertain, and when a forecast depends upon forecasts of related (causal) variables. For example, forecasts of no change were found to be more accurate than trend forecasts for annual sales when there was substantial uncertainty in the trend lines (e.g., Schnaars and Bavuso 1986). This principle also implies that forecasts should revert to longterm trends when such trends have been firmly established, do not waver, and there are no firm reasons to suggest that they will change. Finally, trends should be damped toward no change as the forecast horizon increases.

These conclusions were drawn from the forecasting principles in the edited handbook on forecasting (Armstrong 2001) and they are described at forecastingprinciples.com. A summary of the principles, now numbering 140, is provided in the Forecasting Audit on the site, where they are presented as a checklist.

\section{The Forecasting Problem}

In determining the best policies to deal with the climate of the future, a policy maker first has to select an appropriate statistic to use to represent the changing climate. By convention, the statistic is the averaged global temperature as measured with thermometers at ground stations throughout the world, though in practice this is a far from satisfactory metric (e.g., Essex et al., 2007).

It is then necessary to obtain forecasts and prediction intervals for each of the following:

1. What will happen to the mean global temperature in the long-term (say 20 years or longer)?

2. If accurate forecasts of mean global temperature changes can be obtained and these changes are substantial, then it would be necessary to forecast the effects of the changes on the health of living things and on the health and wealth of humans. The concerns about changes in global mean temperature are based on the assumption that the earth is currently at the optimal temperature and that variations over years (unlike variations within years) are undesirable. For a proper assessment, costs and benefits must be comprehensive. (For example, policy responses to Rachel Carson's Silent Spring should have been based in part on forecasts of the number of people who might die from malaria if DDT use were reduced).

3. If reliable forecasts of the effects of the temperature changes on the health of living things and on the health and wealth of humans can be obtained and the forecasts are for substantial harmful effects, then it would be necessary to forecast the costs and benefits of alternative policy proposals. 
4. If reliable forecasts of the costs and benefits of alternative policy proposals can be obtained and at least one proposal is predicted to lead to net benefits, then it would be necessary to forecast whether the policy changes can be implemented successfully.

If reliable forecasts of policy implementation can be obtained and the forecasts clearly support net benefits for the policy, and the policy can be successfully implemented, then the policy proposal should be implemented. A failure to obtain scientifically validated forecasts at any stage would render subsequent stages irrelevant. Thus, we focus on the first of the four forecasting problems.

Is it necessary to use scientific forecasting methods? In other words, to use methods that have been shown by empirical validation to be relevant to the types of problems involved with climate forecasting? Or is it sufficient to have leading scientists examine the evidence and make forecasts? We address this issue before moving on to our audits.

\section{On the value of forecasts by experts}

Many policy decisions are based on forecasts by experts. Research on persuasion has shown that people have substantial faith in the value of such forecasts. Faith increases when experts agree with one another.

Our concern is with what we refer to as unaided expert judgments. In such cases, experts may have access to empirical studies and other information, but they use their knowledge to make predictions without the aid of well-established forecasting principles. Thus, they could simply use the information to come up with judgmental forecasts. Alternatively, they could translate their beliefs into mathematical statements (or models) and use those to make forecasts.

Although they may seem convincing at the time, expert forecasts make for humorous reading in retrospect. Cerf and Navasky's (1998) book contains 310 pages of examples, such as Fermi Award-winning scientist John von Neumann's 1956 prediction that "A few decades hence, energy may be free". Examples of expert climate forecasts that turned out to be completely wrong are easy to find, such as UC Davis ecologist Kenneth Watt's prediction in a speech at Swarthmore College on Earth Day, April 22, 1970 that, "If present trends continue, the world will be about four degrees colder in 1990, but eleven degrees colder in the year 2000. This is about twice what it would take to put us into an ice age"

Are these examples merely a matter of selective perception? The first author's review of empirical research on this problem led to the "Seer-sucker theory," stating that, "No matter how much evidence exists that seers do not exist, seers will find suckers" (Armstrong 1980). The amount of expertise does not matter beyond a basic minimum level. There are exceptions to the Seer-sucker Theory: When experts get substantial well-summarized feedback about the accuracy of their forecasts and about the reasons why their forecasts were or were not accurate, they can improve their forecasting. This situation applies for short-term (up to five day) weather forecasts, but we are not aware of any such regime for long-term global climate forecasting. Even if there were such a regime, the feedback would trickle in over many years before it became useful for improving forecasting.

Research since 1980 has added support to the Seer-sucker Theory. In particular, Tetlock (2005) recruited 284 people whose professions included, "commenting or offering advice on political and economic trends." He asked them to forecast the probability that various situations would or would not occur, picking areas (geographic and substantive) within and outside their areas of expertise. By 2003, he had accumulated over 82,000 forecasts. The experts barely if at all outperformed non-experts and neither group did well against simple rules.

Comparative empirical studies have routinely concluded that judgmental forecasting by experts is the least accurate of the methods available to make forecasts. For example, Ascher 
(1978, p. 200), in his analysis of long-term forecasts of electricity consumption found that was the case.

Experts' forecasts of climate changes have long been popular. Anderson and Gainor (2006) found the following headlines in their search of the New York Times:

$\begin{array}{ll}\text { Sept. 18, } 1924 & \text { "MacMillan Reports Signs of New Ice Age" } \\ \text { March 27, } 1933 & \text { "America in Longest Warm Spell Since 1776" } \\ \text { May 21, 1974 } & \begin{array}{l}\text { "Scientists Ponder Why World's Climate is Changing: } \\ \text { A Major Cooling Widely Considered to be Inevitable" }\end{array} \\ \text { Dec. 27, 2005 } & \begin{array}{l}\text { "Past Hot Times Hold Few Reasons to Relax About New } \\ \text { Warming" }\end{array}\end{array}$

In each case, the forecasts were made with a high degree of confidence.

In the mid-1970s, there was a political debate raging about whether the global climate was changing. The United States' National Defense University (NDU) addressed this issue in their book, Climate Change to the Year 2000 (NDU 1978). This study involved nine man-years of effort by Department of Defense and other agencies, aided by experts who received honoraria, and a contract of nearly $\$ 400,000$ (in 2007 dollars). The heart of the study was a survey of experts. It provided them with a chart of "annual mean temperature, $0-80^{\circ} \mathrm{N}$. latitude," that showed temperature rising from 1870 to early 1940 then dropping sharply up to 1970 . The conclusion, based primarily on 19 replies weighted by the study directors, was that while a slight increase in temperature might occur, uncertainty was so high that "the next twenty years will be similar to that of the past" and the effects of any change would be negligible. Clearly, this was a forecast by scientists, not a scientific forecast. However, it proved to be quite influential. The report was discussed in The Global 2000 Report to the President (Carter) and at the World Climate Conference in Geneva in 1979.

The methodology for climate forecasting used in the past few decades has shifted from surveys of experts' opinions to the use of computer models. However, based on the explanations that we have seen, such models are, in effect, mathematical ways for the experts to express their opinions. To our knowledge, there is no empirical evidence to suggest that presenting opinions in mathematical terms rather than in words will contribute to forecast accuracy. For example, Keepin and Wynne (1984) wrote in the summary of their study of the International Institute for Applied Systems Analysis's "widely acclaimed" projections for global energy that, "Despite the appearance of analytical rigour... [they] are highly unstable and based on informal guesswork". Things have changed little since the days of Malthus in the 1800 s, when he predicted that the demand for food would outpace supply, thus leading to mass starvation. He expressed his opinions mathematically: in his model, the supply of food increased arithmetically while population grew at a geometric rate. His mathematical model predicted inevitable starvation.

International surveys of climate scientists from 27 countries, obtained by Brat and von Storch in 1996 and 2003, were summarized by Bast and Taylor (2007). Many scientists were skeptical about the predictive validity of climate models. Of more than 1,060 respondents, 35\% agreed with the statement, "Climate models can accurately predict future climates," and 47\% percent disagreed. Members of the general public were also divided. An Ipsos Mori poll of 2031 people aged 16 and over found that $40 \%$ agreed that "climate change was too complex and uncertain for scientists to make useful forecasts", while 38\% disagreed (Eccleston 2007). 


\section{An examination of climate forecasting methods}

Our search for prior reviews of long-term climate forecasting processes yielded nine independent reviews.

We also assessed the extent to which those who have made climate forecasts used evidence-based forecasting procedures. We did this by conducting Google searches.

We then conducted a "forecasting audit." The key aspects of such an audit are that:

- all elements of the forecasting process are examined,

- each principle against which the forecasting process is examined is supported by evidence or is self-evidently true and unchallenged by evidence,

- the forecasting process is independently rated against each principle, preferably by more than one rater, and

- the audit is fully disclosed.

To our knowledge, no one has ever published a paper that is based on a forecasting audit, as defined here. We suspect, however, that such audits have been done for private firms. We suggest that for forecasts involving public policy, such audits should be expected and perhaps even required. In addition, they should be fully disclosed with respect to who did the audit, what biases might be involved, and what were the detailed findings from the audit.

\section{Reviews of climate forecasts}

We could not find any comprehensive reviews of climate forecasting efforts. With the exception of Stewart and Glantz (1985), the reviews did not refer to evidence-based findings. None of the reviews provided explicit ratings of the processes and, again with the exception of Stewart and Glantz, little attention was given to full disclosure of the reviewing process. Finally, some reviews ignored the forecasting methods and focused on the accuracy of the forecasts.

Stewart and Glantz (1985) conducted an audit of the National Defense University (NDU 1978) forecasting process that was described above. They were critical of the report because it lacked an awareness of proper forecasting methodology. Their audit was hampered because the organizers of the study said that the raw data had been destroyed and a request to the Institute for the Future about the sensitivity of the forecasts to the weights went unanswered. Judging from a Google Scholar search, climate forecasters have paid little attention to this paper.

Carter, et al. (2006) examined the Stern Review (Stern 2007). They concluded that the authors of the Report made predictions without reference to scientific validation and without proper peer review.

Pilkey and Pilkey-Jarvis (2007) concluded that the long-term climate forecasts they examined were based only on the opinions of the scientists. The scientists' opinions were expressed in complex mathematical terms without any evidence on the validity of chosen approach. The authors provided the following quotation on their page 45 to summarize their assessment: "Today's scientists have substituted mathematics for experiments, and they wander off through equation after equation and eventually build a structure which has no relation to reality (Nikola Telsa, inventor and electrical engineer, 1934)." While it is sensible to be explicit about beliefs and to formulate these in a model, forecasters must also demonstrate that the relationships are valid.

Carter (2007) examined evidence on the predictive validity of the general circulation models (GCMs) used by the IPCC scientists. He found that while the models included some basic principles of physics, scientists had to make "educated guesses" about the values of many parameters because knowledge about the physical processes of the earth's climate is incomplete. In practice, the GCMs failed to predict recent global average temperatures as accurately as simple 
curve-fitting approaches (Carter 2007, pp. 64 - 65). They also forecast greater warming at higher altitudes in the tropics when the opposite has been the case (p. 64). Further, individual GCMs produce widely different forecasts from the same initial conditions and minor changes in parameters can result in forecasts of global cooling (Essex and McKitrick, 2002). Interestingly, when models predict global cooling, the forecasts are often rejected as "outliers" or "obviously wrong" (e.g., Stainforth et al., 2005).

Roger Pielke Sr. gave an assessment of climate models in a 2007 interview (available at http://climatesci.colorado.edu/2007/04/30/interview-by-marcel-crok-of-roger-a-pielke-sr-jan2007/):

You can always reconstruct after the fact what happened if you run enough model simulations. The challenge is to run it on a independent dataset, say for the next five years. But then they will say "the model is not good for five years because there is too much noise in the system". That's avoiding the issue then. They say you have to wait 50 years, but then you can't validate the model, so what good is it?

...Weather is very difficult to predict; climate involves weather plus all these other components of the climate system, ice, oceans, vegetation, soil etc. Why should we think we can do better with climate prediction than with weather prediction? To me it's obvious, we can't!

I often hear scientists say "weather is unpredictable, but climate you can predict because it is the average weather". How can they prove such a statement?

Bellamy and Barrett (2007) found serious deficiencies in the general circulation models described in the IPCC's Third Assessment Report. In particular, the models (1) produced very different distributions of clouds and none was close the actual distribution of clouds, (2) parameters for incoming radiation absorbed by the atmosphere and for that absorbed by the Earth's surface varied considerably, (3) did not accurately represent what is known about the effects of $\mathrm{CO}_{2}$ and could not represent the possible positive and negative feedbacks about which there is great uncertainty. The authors concluded:

The climate system is a highly complex system and, to date, no computer models are sufficiently accurate for their predictions of future climate to be relied upon. (p. 72)

Trenberth (2007), a lead author of Chapter 3 in the IPCC WG1 report wrote in a Nature.com blog "... the science is not done because we do not have reliable or regional predictions of climate."

Taylor (2007) compared seasonal forecasts by New Zealand's National Institute of Water and Atmospheric Research (NIWA) with outcomes for the period May 2002 to April 2007. He found NIWA's forecasts of average regional temperatures for the season ahead were, at $48 \%$ correct. No more accurate than chance. That this is a general result was confirmed by New Zealand climatologist Dr Jim Renwick, who observed that NIWA's low success rate was comparable to that of other forecasting groups worldwide. He added that "Climate prediction is hard, half of the variability in the climate system is not predictable, and so we don't expect to do terrifically well." Dr Renwick is an author on Working Group I of the IPCC 4th Assessment Report, and also serves on the World Meteorological Organization Commission for Climatology Expert Team on Seasonal Forecasting. His expert view is that current GCM climate models are unable to predict future climate any better than chance (New Zealand Climate Science Coalition 2007).

Similarly, Vizard, Anderson, and Buckley (2005) found seasonal rainfall forecasts for Australian townships were insufficiently accurate to be useful to intended consumers such as farmers planning for feed requirements. The forecasts were released only 15 days ahead of each three month period. 


\section{Climate forecasters' use of the scientific literature on forecasting methods}

In April 2007, we used the Advanced Search function of Google Scholar to get a general sense of the extent to which environmental forecasters use scientific literature on forecasting methods. When we searched for "global warming" and "forecasting principles," we found no relevant sites. Nor did we find any relevant sites for "forecastingprinciples.com" and "global warming." Nor were there any relevant sites mentioned for the relevant-sounding paper, "Forecasting for Environmental Decision-Making" (Armstrong 1999) published in a book with a relevant title: Tools to Aid Environmental Decision Making.

We examined the references in Chapter 8 (on evaluation) of the 2007 Intergovernmental Panel on Climate Change's Working Group One report. There were 788 references. Of these, none had any apparent relationship to forecasting methodology. The task was not that difficult as most papers had titles such as "Using stable water isotopes to evaluate basin-scale simulations of surface water budgets," and "Oceanic isopycnal mixing by coordinate rotation."

It is hard to understand how scientific forecasting could be conducted without any reference to the literature on how to make such forecasts. At a minimum, one would expect to see some empirical justification for the forecasting methods that were used.

\section{A survey to identify the most important long-term forecasts of global temperature}

We conducted a survey of scientists involved in long-term climate forecasting and policy makers. Our primary concern was to identify the most important forecasts and how those forecasts were made. In particular, we wished to know if the most widely accepted forecasts of global average temperature were based on the opinions of experts or on scientific forecasting methods. Given the conclusion from our Google search that many scientists are unaware of evidence-based findings related to forecasting methods, our hypothesis was that the forecasts were based on the opinions of scientists.

We sent a questionnaire to experts who had expressed diverse opinions on global warming. We generated lists of experts by identifying key people and asking them to identify others. (The lists are provided in Appendix A.) Most (70\%) of the 240 experts on our lists were IPCC reviewers and authors.

The questionnaire asked the experts to provide references for what they regarded as the most credible source of long-term forecasts of mean global temperatures.

We strove for simplicity to minimize resistance to our request. Even busy people should have time to send a few references, especially if they believe that it is important to evaluate the quality of the forecasts that will influence major decisions.

We received useful responses from 51 people, 42 of whom provided references to what they regarded as credible sources of long-term forecasts of mean global temperatures. Interestingly, eight respondents provided references in support of their claims that no credible forecasts exist. Of the 42 expert respondents who were associated with global warming views, 30 referred us to the IPCC's report.

Based on the replies to this survey, it was clear that the IPCC's Working Group 1 Report contained the forecasts that are viewed as most credible by the bulk climate community. These forecasts are contained in Chapter 10 of the Report and the models that are used to forecast climate are assessed in Chapter 8, "Climate Models and Their Evaluation" (Randall et al. 2007). Chapter 8 provided the most useful information on the forecasting process used by the IPCC to derive forecasts of mean global temperatures, so we audited that chapter. 


\section{A forecasting audit for global warming}

Interestingly, some IPCC climate forecasters claim that the IPCC does not provide forecasts but rather presents scenarios or "projections." However, the word "forecast" and its derivatives occurred 37 times, and "predict" and its derivatives occurred 90 times in the body of Chapter 8 . Recall also that most of our respondents (29 of whom were IPCC authors or reviewers) nominated the IPCC report as the most credible source of forecasts (not "projections") of global average temperature.

Chapter 8 was, in our judgment, poorly written. The writing showed little concern for the target readership, provided extensive detail on items that are of little interest in judging the merits of the forecasting process, provided references without describing what readers might find, and imposed an incredible burden on readers by providing 788 references. The readability of the chapter was low. For example, Section 8.2.1.3 "Parameterization," a critical section for understanding the forecasting process, scored 23 for Flesch-Kinkaid Reading Ease ("plain English" is 60 and the Harvard Law Review scores 32), and a "grade level" Gunning-Fog Index of 21. In addition, the Chapter reads in places like a sales brochure; in the three-page executive summary, the terms, "new" and "improved" and related derivatives appeared 17 times. Most significantly, the chapter omitted key details on the assumptions and the forecasting process that were used.

We each made a formal, independent audit of IPCC Chapter 8 in May 2007. To do so, we used the Forecasting Audit software on the forecastingprinciples.com site, which is based on material originally published in Armstrong (2001). To our knowledge, it is the only evidencebased tool for evaluating forecasting procedures.

While Chapter 8 required many hours to read, it took us each about one hour to rate the forecasting approach described in the Chapter using the Audit software. We have each been involved with developing the Forecasting Audit program, so other users would likely require much more time. Ratings are on a 5-point scale from -2 to +2 . A rating of +2 indicates the forecasting procedures were consistent with a principle, and a rating of -2 indicates failure to comply with a principle. The Audit software also has options to indicate that there is insufficient information to rate the procedures or that the principle is not relevant to a particular forecasting problem.

Our initial overall average ratings were similar at -1.37 and -1.35 . We compared our individual ratings for individual principles and discussed inconsistencies. In some cases we averaged the ratings, truncating toward zero, in other cases we decided that there was insufficient information or that the information was too ambiguous to rate with confidence. Our final ratings are fully disclosed in the Special Interest Group section of the forecastingprinciples.com site that is devoted to Public Policy (publicpolicyforecasting.com).

Of the 140 principles in the Forecasting Audit, we judged that 127 were relevant for auditing the forecasting problem addressed in Chapter 8 . The Chapter provided insufficient information to rate the forecasting procedures that were used against 38 of these principles. For example, we did not rate the Chapter against Principle 10.2, "Use all important variables." At least in part, our difficulty in auditing the Chapter was due to the fact that it was abstruse. It was sometimes difficult to know whether the information we sought was present or not.

Of the 89 forecasting principles that we were able to rate, the Chapter violated 72. Adherence to some of the key principles is necessary for forecasts to be valid. We address three such principles, all based on strong empirical evidence: violation of any one of them would render the IPCC climate forecasts invalid. All three of these key principles were violated by the forecasting procedures described in IPCC Chapter 8. We key these principles to their numbering in the Forecasting Audit software. 


\section{Principle 1.4: Consider whether a formal forecasting procedure can beat a naïve method}

This principle refers to whether a forecasting method can be developed that would do better than a naïve method such as predicting that the weather next May will be the same as the weather last May.

Interestingly, naïve methods are often strong competitors. This is especially so when there is much uncertainty. To the extent that uncertainty is high, forecasters should emphasize the naïve method. (This is illustrated by regression model coefficients: when uncertainty increases, the coefficients tend towards zero.) Departures from the naïve model tend to increase forecast error when uncertainty is high.

In our judgment, the uncertainty in forecasting global mean temperature is extremely high. For example, there is controversy among climate scientists over the current trend. One researcher, Carter (2007, p. 67) wrote:

...the slope and magnitude of temperature trends inferred from time-series data depend upon the choice of data end points. Drawing trend lines through highly variable, cyclic temperature data or proxy data is therefore a dubious exercise. Accurate direct measurements of tropospheric global average temperature have only been available since 1979, and they show no evidence for greenhouse warming. Surface thermometer data, though flawed, also show temperature stasis since 1998.

Global climate is complex. Scientific evidence on many key relationships is weak or absent; e.g., does increased $\mathrm{CO}_{2}$ in the atmosphere cause high temperatures or do high temperatures increase $\mathrm{CO}_{2}$ (e.g. Jaworowski 2007)? Measurements of key variables such as local temperatures and a representative global temperature are contentious in the case of modern measurements, because of the distribution of weather stations and possible artifacts such as the urban heat island effect, and often speculative in the case of ancient ones, such as those climate proxies derived from tree ring and ice-core data (Carter 2007). Finally, it is difficult to forecast the causal variables.

The already high level of uncertainty rises rapidly as the forecast horizon increases.

While the authors of Chapter 8 claim that the forecasts of global mean temperature are wellfounded, their language is imprecise and relies heavily on such words as "generally," "reasonable well," "widely," and "relatively" [to what?]. The report makes many explicit references to uncertainty. For example, the phrases ". . . it is not yet possible to determine which estimates of the climate change cloud feedbacks are the most reliable" and "Despite advances since the TAR, substantial uncertainty remains in the magnitude of cryospheric feedbacks within AOGCMs" appear on p. 593. In discussing the modeling of temperature, the authors wrote, "The extent to which these systematic model errors affect a model's response to external perturbations is unknown, but may be significant" (p. 608), and, "The diurnal temperature range... is generally too small in the models, in many regions by as much as 50\%" (p. 609), and "It is not yet known why models generally underestimate the diurnal temperature range." The following words and phrases appear at least once in the Chapter: unknown, uncertain, unclear, not clear, disagreement, uncertain, not fully understood, appears, not well observed, variability, variety, difference, unresolved, not resolved, and poorly understood.

Given the high uncertainty, the appropriate naïve method for this situation would be the "nochange" model. Remarkably, nowhere does the IPCC Report address the issue of forecastability. It should have been addressed prior to spending enormous sums on complex forecasting models.

In effect, given the current state of uncertainty regarding climate, prior evidence on forecasting methods suggests that attempts to improve upon the naïve model might increase 
forecast error. To reverse this conclusion, one would have to produce validated evidence in favor of alternative methods. Such evidence is not provided in Chapter 8 of the IPCC report.

We are not suggesting that climate change cannot be forecast, only that this has yet to be demonstrated. We expect that such methods as the naïve model with drift, rule-based forecasting, well-specified simple causal models, and combined forecasts might prove useful. All of those methods are discussed in Armstrong (2001). To our knowledge, none of them has been examined to date.

\section{Principle 9.3: Do not use fit to develop the model.}

It was not clear to us to what extent the models produced by the IPCC are either based on, or have been tested against, sound empirical data. However, some statements were made about the ability of the models described in Chapter 8 to fit historical data, after tweaking their parameters.

Extensive research has shown that the ability of models to fit historical data has little relationship to forecast accuracy (See "Evaluating Methods" in Armstrong 2001.) It is well known that fit can be improved by making a model more complex. The consequence of increasing complexity to improve fit, however, is to decrease the accuracy of forecasts. The 12 authors of Chapter 8 appeared to be unaware of this principle.

\section{Principle 13.26: Use out-of-sample data to test the forecasts.}

Chapter 8 did not provide evidence on the accuracy of ex ante long-term forecasts from the models used to generate the IPCC's forecasts of climate change. It would have been feasible to assess the accuracy of alternative forecasting methods for short- and medium-term forecasts by using "successive updating." This involves withholding data on a number of years, then providing forecasts for one-year ahead, then two-years ahead, and so on up to, say, 20 years. The actual years could be disguised during these validation procedures. Furthermore, the years could be reversed (without telling the forecasters) to assess back-casting accuracy. If, as is suggested by forecasting principles, the models were unable to improve on the accuracy of forecasts from the naïve method in such tests, there would be no reason to suppose that accuracy would improve for longer forecasts.

\section{Summary of audit findings}

A list of the 72 violations of forecasting principles by the IPCC forecasting procedures is provided on the Public Policy Special Interest Group Page at forecastingprinciples.com. The many violations provide further evidence that the IPCC authors were unaware of evidence-based principles for forecasting. If they were aware of them, it would have been incumbent on them to present evidence to justify their departures from best forecasting practice. They did not do so. We conclude that because the forecasting processes examined in Chapter 8 overlook scientific evidence on forecasting, the IPCC forecasts of climate change are not scientific.

We invite others to provide evidence-based audits of Chapter 8. As with peer review, we will require all relevant information on the people who conduct the audits prior to posting the audits.

The Forecasting Audit should be used early and often by climate change forecasters and their clients, as it should be by those involved in other public policy issues such as national health plan proposals and proposals for gun control. Doing so would help to ensure that they are using appropriate forecasting procedures. Outside evaluators should also be encouraged to conduct audits. The audit reports should be made available to both the sponsors of the study and the public by posting on an open web site such as publicpolicyforecasting.com. 


\section{Conclusions}

To provide forecasts of climate change that are useful for policy-making, one would need to prepare forecasts of (1) global temperature, (2) the effects of any temperature change, (3) the effects of proposed policy changes, and (4) whether the best policies would be successfully implemented. A failure to properly forecast for any of these four problems would nullify any value for policy making.

The Stern Review concluded that, "The scientific evidence is now overwhelming; climate change presents very serious global risks, and it demands an urgent global response" (Stern 2007, p. Xv). We have not been able to find any scientific evidence to support such a claim.

We have shown that failure occurs at the first stage of analysis. Specifically, we have been unable to find a scientific forecast to support the currently widespread belief in "global warming." Prior research on forecasting suggests that a naïve (no change) forecast would be superior to current predictions which are, in effect, experts' judgments.

Based on our Google searches, those forecasting long-term climate change have no apparent knowledge of evidence-based forecasting methods, so we expect that the same conclusions would apply to the other three necessary parts of the forecasting problem.

By relying on evidence-based forecasting methods, we conclude that policies founded on predictions of man-made global warming from models based on the opinions of scientists will be harmful.

Given the conditions involved in long-term global forecasts and the high uncertainty involved, prior research on forecasting suggests that even if the forecasting methods were properly applied, it may not be possible to improve upon the naïve, "no-change," forecast. We do not even have evidence that it is possible to make useful medium term (e.g., one to five year) forecasts.

Our paper is concerned with rational assessments of public policy, not with public opinions. People will continue to believe that serious manmade global warming exists as they will continue to believe other things that have no scientific support (e.g., the biblical creation story, astrology, minimum wages to help poor people, and so on), and public opinion can be intense on such issues. Public policy makers should, however, be concerned with how to move away from emotions and towards rational scientific analysis.

One might say that it is important to consider steps to prevent global warming, but we have the same level of confidence in saying that we should take steps to prevent global cooling. The more important question is "what is the best way to invest our resources for the benefit of mankind?" This would lead to such trade-offs as asking whether it is better to spend a dollar on reducing AIDS or air pollution or malaria or breast cancer, where we know what policies will work, or to spend it on controlling future climate, where uncertainty about the situation is high. Given the large uncertainties of climate change science, government polices on climate control are unwarranted and will reduce the well-being of the great majority of people who are not the beneficiaries of the wealth redistribution that will occur as a result of such policies. Advocates owe it to the people who would be affected by the policies they recommend to base their advocacy on scientific forecasts that address all four of the key areas that are necessary for a rational analysis of the problem. We hope that before committing resources, decision makers will insist on scientific forecasts rather than accept the opinions of some scientists. 


\section{Acknowledgements}

Kay A. Armstrong, Bob Carter, Robert Fildes, Paul Goodwin, Jos de Laat, Ross McKitrick, and Tom Yokum made helpful suggestions on various drafts of the paper. Hester Green tracked down contact information for our survey.

\section{References}

Anderson, R.W. and Gainor, D. (2006). Fire and Ice: Journalists have warned of climate change for 100 years, but can't decide weather we face an ice age or warming. Business and Media Institute, May 17. Available at http://www.businessandmedia.org/specialreports/2006/fireandice/FireandIce.pdf

Armstrong, J.S. (1980). The Seer-sucker theory: The value of experts in forecasting. Technology Review 83 (June-July), 16-24.

Armstrong, J.S. (1978; 1985). Long-Range Forecasting: From Crystal Ball to Computer. New York: Wiley-Interscience.

Armstrong, J.S. (1999). Forecasting for environmental decision-making, in Dale, V.H. and English, M.E. eds., Tools to Aid Environmental Decision Making. New York: Springer-Verlag, 192-225.

Armstrong, J.S. (2001). Principles of Forecasting: A Handbook for Researchers and Practitioners. Kluwer Academic Publishers.

Armstrong, J.S. (2006). Findings from evidence-based forecasting: Methods for reducing forecast error. International Journal of Forecasting, 22, 583-598.

Ascher W. (1978). Forecasting: An Appraisal for Policy Makers and Planners. Baltimore: Johns Hopkins University Press.

Bast, J. and Taylor, J.M. (2007). Scientific consensus on global warming. The Heartland Institute: Chicago, Illinois. Available http://downloads.heartland.org/20861.pdf. [The responses to all questions in the 1996 and 2003 surveys by Brat and von Storch are included as an appendix.]

Bellamy, D. and Barrett, J. (2007). Climate stability: an inconvenient proof. Proceedings of the Institution of Civil Engineers - Civil Engineering, 160, 66-72.

Carter, R.M. (2007). The myth of dangerous human-caused climate change. The Aus/MM New Leaders Conference, Brisbane May 3, 2007. Full text available from http://members.iinet.net.au/ glrme/new page $1 . \mathrm{htm}$

Carter, R.M., de Freitas, C.R., Goklany, I.M., Holland, D. and Linzen, R.S. (2006). The Stern review: A dual critique: Part 1. World Economics, 7, 167-198.

Cerf, C. and Navasky, V. (1998). The Experts Speak. New York: Pantheon. Baltimore, MD: Johns Hopkins University Press.

Craig, P.P., Gadgil, A., and Koomey, J.G. (2002). What Can History Teach Us? A Retrospective Examination of Long-Term Energy Forecasts for the United States. Annual Review of Energy and the Environment, 27, 83-118.

Eccleston, P. (2007). Public 'in denial' about climate change. telegraph.co.uk, 12:01 BST 03/07/2007. Available at http://www.telegraph.co.uk/core/Content/displayPrintable.jhtml;jse...MGSFFOAVCBQWIV0?xm $\underline{1=/ \text { earth } / 2007 / 07 / 03 / \text { eawarm103.xml\&site }=30 \text { \&page }=0}$

Essex, C., McKitrick, R. and Andresen, B. (2007). Does a global temperature exist? Journal of NonEquilibrium Thermodynamics, 32, 1-27. Working paper available at http://www.uoguelph.ca/ rmckitri/research/globaltemp/globaltemp.html

Essex, C. and McKitrick, R. (2002). Taken by Storm. The Troubled Science, Policy \& Politics of Global Warming, Toronto: Key Porter Books. 
Jaworowski, Z. (2007). $\mathrm{CO}_{2}$ : The greatest scientific scandal of our time. Executive Intelligence Review, 34(11), 38-53. Available at http://www.warwickhughes.com/icecore/zjmar07.pdf

Keepin, B. and Wynne, B. (1984). Technical analysis of IIASA energy scenarios. Nature, 312, 691-695.

NDU (1978). Climate Change to the Year 2000. Washington, D.C.: National Defense University.

New Zealand Climate Science Coalition (2007). World climate predictors right only half the time. Media release 7 June. Available at http://www.scoop.co.nz/stories/SC0706/S00026.htm

Pilkey, O.H. and Pilkey-Jarvis, L. (2007). Useless Arithmetic Why Environmental Scientists Can't predict the Future. New York: Columbia University Press.

Randall, D.A., Wood, R.A., Bony, S., Colman, R., Fichefet, T., Fyfe, J., Kattsov, V., Pitman, A., Shukla, J., Srinivasan, J., Stouffer, R. J., Sumi, A. and Taylor, K.E. (2007). Climate Models and Their Evaluation, in Solomon, S., Qin, D., Manning, M., Chen, Z., Marquis, M., Averyt, K.B., Tignor, M. and Miller, H.L. eds., Climate Change 2007: The Physical Science Basis. Contribution of Working Group I to the Fourth Assessment Report of the Intergovernmental Panel on Climate Change. Cambridge, UK and New York, NY, USA: Cambridge University Press.

Schnaars, S.P. and Bavuso, R.J. (1986). Extrapolation models on very short-term forecasts. Journal of Business Research, 14, 27-36.

Stainforth, D.A., Aina, T., Christensen, C., Collins, M., Faull, N., Frame, D.J., Kettleborough, J.A., Knight, S., Martin, A., Murphy, J.M., Piani, C., Sexton, D., Smith, L.A., Spicer, R.A., Thorpe, A.J. and Allen, M.R. (2005). Uncertainty in predictions of the climate response to rising levels of greenhouse gases, Nature, 433, 403-406.

Stern, N. (2007). The Economics of Climate Change: The Stern Review. New York: Cambridge University Press. Available from http://www.hmtreasury.gov.uk/independent_reviews/stern_review_economics_climate_change/ste rnreview index.cfm

Stewart, T.R. and Glantz, M.H. (1985). Expert judgment and climate forecasting: A methodological critique of 'Climate Change to the Year 2000'. Climate Change, 7, 159-183.

Taylor, M. (2007). An evaluation of NIWA's climate predictions for May 2002 to April 2007. Climate Science Coalition. Available at http://www.climatescience.org.nz/assets/2007691051580.ClimateUpdateEvaluationText.pdf Data available at http://www.climatescience.org.nz/assets/2007691059100.ClimateUpdateEvaluationCalc.xls.pdf

Tetlock, P.E. (2005). Expert Political Judgment: How Good Is It? How Can We Know? Princeton, NJ: Princeton University Press.

Trenberth, K.E. (2007). Predictions of climate. Climate Feedback: The Climate Change Blog, June 4. Available at http://blogs.nature.com/climatefeedback/2007/06/predictions_of_climate.html

Vizard, A.L., Anderson, G.A., and Buckley, D.J. (2005). Verification and value of the Australian Bureau of Meteorology township seasonal rainfall forecasts in Australia, 1997-2005. Meteorological Applications, 12, 343-355. 
Appendix A: People to whom we sent our questionnaire (* indicates a relevant response)

\section{IPCC Working Group 1}

Myles Allen, Richard Alley, Ian Allison, Peter Ambenje, Vincenzo Artale, Paulo Artaxo, Alphonsus Baede, Roger Barry, Terje Berntsen, Richard A. Betts, Nathaniel L. Bindoff, Roxana Bojariu, Sandrine Bony, Kansri Boonpragob, Pascale Braconnot, Guy Brasseur, Keith Briffa, Aristita Busuioc, Jorge Carrasco, Anny Cazenave, Anthony Chen*, Amnat Chidthaisong, Jens Hesselbjerg Christensen, Philippe Ciais*, William Collins, Robert Colman*, Peter Cox, Ulrich Cubasch, Pedro Leite Da Silva Dias, Kenneth L. Denman, Robert Dickinson, Yihui Ding, JeanClaude Duplessy, David Easterling, David W. Fahey, Thierry Fichefet*, Gregory Flato, Piers M. de F. Forster*, Pierre Friedlingstein, Congbin Fu, Yoshiyuki Fuji, John Fyfe, Xuejie Gao, Amadou Thierno Gaye*, Nathan Gillett*, Filippo Giorgi, Jonathan Gregory*, David Griggs, Sergey Gulev, Kimio Hanawa, Didier Hauglustaine, James Haywood, Gabriele Hegerl*, Martin Heimann*, Christoph Heinze, Isaac Held*, Bruce Hewitson, Elisabeth Holland, Brian Hoskins, Daniel Jacob, Bubu Pateh Jallow, Eystein Jansen*, Philip Jones, Richard Jones, Fortunat Joos, Jean Jouzel, Tom Karl, David Karoly*, Georg Kaser, Vladimir Kattsov, Akio Kitoh, Albert Klein Tank, Reto Knutti, Toshio Koike, Rupa Kumar Kolli, Won-Tae Kwon, Laurent Labeyrie, René Laprise, Corrine Le Quéré, Hervé Le Treut, Judith Lean, Peter Lemke, Sydney Levitus, Ulrike Lohmann, David C. Lowe, Yong Luo, Victor Magaña Rueda, Elisa Manzini, Jose Antonio Marengo, Maria Martelo, Valérie Masson-Delmotte, Taroh Matsuno, Cecilie Mauritzen, Bryant Mcavaney, Linda Mearns, Gerald Meehl, Claudio Guillermo Menendez, John Mitchell, Abdalah Mokssit, Mario Molina, Philip Mote*, James Murphy, Gunnar Myhre, Teruyuki Nakajima, John Nganga, Neville Nicholls, Akira Noda, Yukihiro Nojiri, Laban Ogallo, Daniel Olago, Bette OttoBliesner, Jonathan Overpeck*, Govind Ballabh Pant, David Parker, Wm. Richard Peltier, Joyce Penner*, Thomas Peterson*, Andrew Pitman, Serge Planton, Michael Prather*, Ronald Prinn, Graciela Raga, Fatemeh Rahimzadeh, Stefan Rahmstorf, Jouni Räisänen, Srikanthan (S.) Ramachandran, Veerabhadran Ramanathan, Venkatachalam Ramaswamy, Rengaswamy Ramesh, David Randall*, Sarah Raper, Dominique Raynaud, Jiawen Ren, James A. Renwick, David Rind, Annette Rinke, Matilde M. Rusticucci, Abdoulaye Sarr, Michael Schulz*, Jagadish Shukla, C. K. Shum, Robert H. Socolow*, Brian Soden, Olga Solomina*, Richard Somerville*, Jayaraman Srinivasan, Thomas Stocker, Peter A. Stott*, Ron Stouffer, Akimasa Sumi, Lynne D. Talley, Karl E. Taylor*, Kevin Trenberth*, Alakkat S. Unnikrishnan, Rob Van Dorland, Ricardo Villalba, Ian G. Watterson*, Andrew Weaver*, Penny Whetton, Jurgen Willebrand, Steven C. Wofsy, Richard A. Wood, David Wratt, Panmao Zhai, Tingjun Zhang, De'er Zhang, Xiaoye Zhang, Zong-Ci Zhao, Francis Zwiers*

\section{Union of Concerned Scientists}

Brenda Ekwurzel, Peter Frumhoff, Amy Lynd Luers

\section{Channel 4 "The Great Global Warming Swindle" documentary (2007)}

Bert Bolin, Piers Corbyn*, Eigil Friis-Christensen, James Shitwaki, Frederick Singer, Carl Wunsch*

\section{Wikipedia's list of global warming "skeptics"}

Khabibullo Ismailovich Abdusamatov*, Syun-Ichi Akasofu*, Sallie Baliunas, Tim Ball, Robert Balling*, Fred Barnes, Joe Barton, Joe Bastardi, David Bellamy, Tom Bethell, Robert Bidinotto, Roy Blunt, Sonja Boehmer, Andrew Bolt, John Brignell*, Nigel Calder, Ian Castles*, George Chilingarian, John Christy*, Ian Clark, Philip Cooney, Robert Davis, David Deming*, David Douglass, Lester Hogan, Craig Idso, Keith Idso, Sherwood Idso, Zbigniew Jaworowski, Wibjorn Karlen, William Kininmonth, Nigel Lawson, Douglas Leahey, David Legates, Richard Lindzen*, Ross Mckitrick*, Patrick Michaels, Lubos Motl*, Kary Mullis, Tad Murty, Tim Patterson, Benny 
Peiser*, Ian Plimer, Arthur Robinson, Frederick Seitz, Nir Shaviv, Fred Smith, Willie Soon, Thomas Sowell, Roy Spencer, Philip Stott, Hendrik Tennekes, Jan Veizer, Peter Walsh, Edward Wegman

\section{Other sources}

Daniel Abbasi, Augie Auer, Jonathan Boston, Daniel Botkin*, Reid Bryson, Robert Carter*, Ralph Chapman, Al Gore, Kirtland C. Griffin*, David Henderson, Christopher Landsea*, Bjorn Lomborg, Tim Osborn, Roger Pielke*, Henrik Saxe, Thomas Schelling*, Matthew Sobel, Nicholas Stern*, Brian Valentine*, Antonio Zichichi. 